\section{FDA rejects over the counter status for emergency contraceptive}

Janice Hopkins Tanne New York

\begin{abstract}
Family planning groups, women's organisations, obstetricians and gynaecologists, legislators, and national newspapers in the United States protested last week at the Food and Drug Administration's refusal to permit sales over the counter (without a prescription) of an emergency contraceptive.
\end{abstract}

In making his decision, Dr Steven Galson, acting director of the FDA's Center for Drug Evaluation and Research, overruled the organisation's own scientific advisory committee and its professional staff.

Many experts said it was an attack on contraception by the anti-abortion Bush administration. But Dr Galson defended the decision, saying it was not politically motivated. Conservative groups said that the contraceptive, called Plan B, would have increased rates of pregnancy among teenagers and that the drug was dangerous.

The FDA rejected the application of the drug company Barr Research for over the counter status for its product, saying the company had not shown that adolescent women could understand the product instructions The FDA has never previously required such information before granting over the counter status.

Its reasons were dismissed as "bogus" and "a red herring" by Dr Scott Spear, an associate professor of paediatrics at the University of Wisconsin-Madison and director of health services for the university's 40000 students.

The contraceptive has been available on prescription in the United States for several years and is available over the counter in 33 countries. It is marketed in the United Kingdom under the name Levonelle-2 and is available from pharmacists, who are obliged to refer to guidelines when supplying it.

It reduces the risk of pregnancy after unprotected intercourse by $85 \%$. It comprises two tablets of $0.75 \mathrm{mg}$ of levonorgestrel-one is taken as soon as possible after unprotected intercourse and the second 12 hours later. They should be taken within 72 hours after intercourse but may be effective even within five days. The drug prevents fertilisation or implantation and has minimal side effects. It is not an "abortion pill."

Susanne Martinez, Planned Parenthood's vice president for public policy, said, "The FDA's scientific advisory committee voted overwhelmingly-23 to four-for OTC [over the counter] status. The FDA's professional staff agreed with the committee. Both were overruled." She could not remember any time that the FDA had overruled its expert committees;

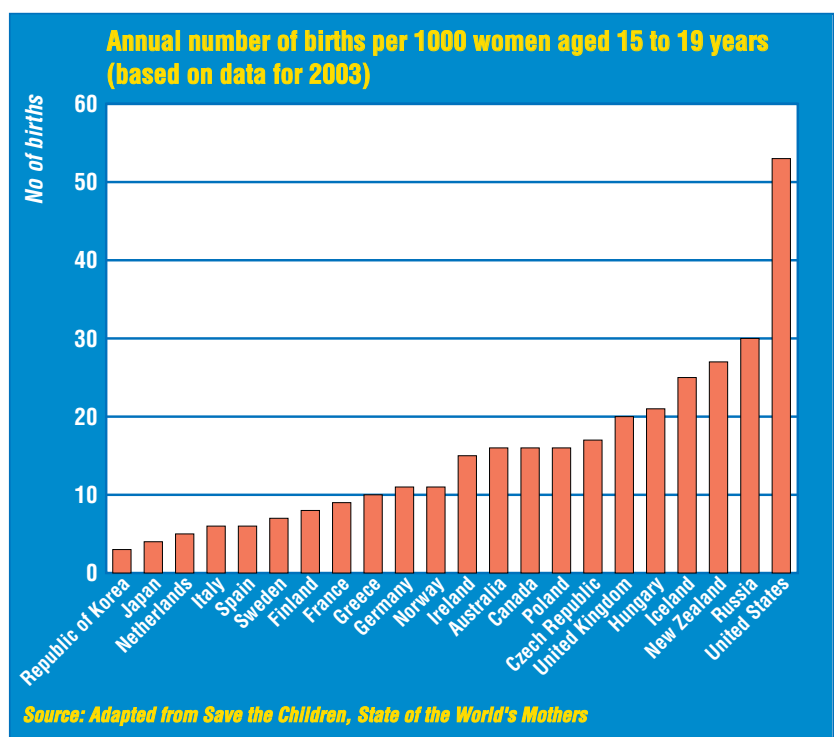

neither could former FDA commissioners.

The United States has one of the world's highest rates of teenage pregnancy and unplanned pregnancy.

Forty one members of the House of Representatives asked the FDA to reconsider. Some asked FDA officials to resign.

The American College of Obstetricians and Gynecologists called the FDA's decision "morally repugnant."

In an editorial the New York Times called the FDA's decision "politically motivated."

\section{Court dismisses appeals of two mothers}

Clare Dyer legal correspondent, BMJ

Two mothers who were trying to get their children back from care have had their appeals dismissed.

But in the first case, two paediatricians who were expert witnesses in a case involving a mother suspected of having Munchausen syndrome by proxy were wrong to conclude, in the absence of a medical explanation, that she had deliberately harmed her child, the Court of Appeal ruled last week.

The child, who had a chromosomal abnormality and was in hospital for failure to thrive, had rigors 11 times while her mother, a paediatric nurse, was in the hospital. Four other experts had said they were unable to conclude that the mother had interfered with the child's cannula.

Elizabeth Butler-Sloss, president of the High Court's family division, said the two paediatricians' postulation that the mother had deliberately interfered with the cannula and administered a harmful substance "rested partly on the foundation that science had no answer and partly on extraneous circumstances culled from the mother's medical history."

She said that the unnamed doctors and the judge, Mrs Justice Bracewell, had fallen into error in concluding that the medical evidence proved the mother had harmed the girl, named only as LB. But there was plenty of nonmedical evidence that was "clear and cogent" on which the judge had been entitled to rely, and the mother's appeal was dismissed.

The mother has lodged complaints with the General Medical \title{
1
}

